\title{
Clinical and Radiological Results after Arthroscopic Superior Capsular Reconstruction in Patients with Massive Irreparable Rotator Cuff Tears
}

\author{
Jeong Yong Yoon, Paul Shinil Kim, Chris Hyunchul Jo ${ }^{1 凶}$ \\ Departments of Orthopedic Surgery, ${ }^{1}$ Orthopedic Surgery and Translational Medicine, SMG-SNU Boramae Medical Center, Seoul, Korea
}

Background: Massive, irreparable rotator cuff tears (RCTs) are a challenging clinical problem in young patients. In recent years, arthroscopic superior capsular reconstruction (ASCR) is a popular treatment in the massive, irreparable RCTs. However, studies reporting clinical results of ASCR are rare in the literature.

Methods: Between 2013 and 2015, six patients underwent ASCR. One patient treated with dermal allograft, while five patients with autogenous fascia lata graft. Demographic data, as well as preoperative and last follow-up clinical data including pain, range of motion (ROM), strength, American Shoulder and Elbow Surgeons system, the Constant system, the University of California at Los Angeles system, the Simple Shoulder Test, and the Shoulder Pain and Disability Index system were obtained. Acromiohumeral distances and Hamada classification were measured on standard anteroposterior x-ray.

Results: All patients were men, and the average age was $59.5 \pm 4.18$ years (range, 53-65 years).The minimum follow-up was 18 months with a mean follow-up was $27.33 \pm 7.58$ months (range, 18-36). All patients had postoperative improvement in pain scores and functional scores. The ROM and strength did not improve after surgery. The Hamada score progressed of radiographic stage in 2 patients. In the case of dermal allograft, there was graft failure 6 weeks after ASCR.

Conclusions: Our results support the ASCR as a viable treatment for surgical salvage in massive, irreparable RCTs. This treatment option may provide patients with decreased pain and increased function. And studying our case of dermal allograft failure provides opportunities to decrease graft failure in ASCR using dermal allograft.

(Clin Shoulder Elbow 2018;21(2):59-66)

Key Words: Superior capsular reconstruction; Rotator cuff tear; Dermal allograft; Autogenous fascia lata graft

\section{Introduction}

Massive, irreparable rotator cuff tears (RCTs) are a complex and difficult problem for many orthopedic surgeons. The appropriate treatment for massive irreparable RCTs is a subject of debate. A surgeon can decide the treatment from debridement, ${ }^{1,}$ partial rotator cuff repair, ${ }^{2,3)}$ latissimus dorsi tendon transfer, ${ }^{4,5)}$ pectoralis major tendon transfer, $\left.{ }^{6}\right)$ graft interposition, ${ }^{7,8)}$ and biodegradable spacer interposition. ${ }^{9,10)}$ The variety of these proce- dures demonstrates the lack of consensus on the optimal treatment of massive, irreparable RCTs. When arthroscopic options are not viable, some surgeons will choose reverse total shoulder arthroplasty (RTSA). ${ }^{11)}$ RTSA is an excellent treatment option for RCTs with and without arthritis in elderly patients. ${ }^{12)}$ However, RTSA is not an optimal or reasonable option in young and active patients. ${ }^{13)}$ Arthroscopic superior capsular reconstruction (ASCR) is a new surgical treatment developed by Mihata et al. ${ }^{14)}$ with the aim of restoring the superior glenohumeral joint instability in the

Received March 19, 2018. Revised April 20, 2018. Accepted April 22, 2018.

Correspondence to: Chris Hyunchul Jo

Department of Orthopedic Surgery, SMG-SNU Boramae Medical Center, 20 Boramae-ro 5-gil, Dongjak-gu, Seoul 07061, Korea

Tel: +82-2-870-2315, Fax: +82-2-870-3864, E-mail: chrisjo@snu.ac.kr, ORCID: https://orcid.org/0000-0002-6161-5442

IRB approval: SMG-SNU Boramae Medical Center (No. 16-2014-5).

Financial support: This work was supported by a clinical research grant-in-aid from the Boramae Medical Center (16-2014-5).

Conflict of interests: None. 
massive, irreparable RCTs. The clinical results on ASCR to date was also published by Mihata et al. ${ }^{15)}$ with 24 shoulders with a mean follow-up of 31 months. Autogenous fascia lata graft was used in this report. In the last several years, multiple surgeons have described technique for ASCR using dermal allograft. ${ }^{16-18)}$ However, studies reporting clinical results of ASCR with dermal allograft or autogenous fascia lata graft are still rare in the literature.

The purpose of this retrospective case series was to show the clinical and radiographic results of the ASCR in the treatment of massive, irreparable RCTs.

\section{Methods}

\section{Study Design}

This retrospective outcome study is a case series performed in single institute. Between January 2013 and December 2015, all patients who had undergone ASCR were included. All patients were fully informed on the characteristics of treatment and gave their written informed consent. The decision to perform surgery was made after failure of conservative treatment for at least 6 months. The inclusion criteria were massive, irreparable RCTs treated with ASCR at our institution. The indications for ASCR was: RCTs with fatty infiltration of muscles (Goutallier grade $\geq 3){ }^{19)}$ no osteoarthritis (<grade 3 in the Hamada classification). ${ }^{20,21)}$ And torn tendon cannot be repaired to their insertion on the tuberosities despite conventional techniques intraoperatively. The exclusion criteria were a history of trauma, cancer, symptomatic cervical spine problems, infection, patient age $>65$ years and the absence of the last follow-up data.

\section{Clinical Outcome Measurement}

The same orthopedic team performed pre- and postoperatively clinical outcome evaluation. For evaluation, each patient completed a questionnaire that consisted of standardized outcome assessments preoperatively and postoperatively. Postoperative measurements at last follow-up were compared to preoperative measurement. Clinical outcome measures include
(1) pain, (2) range of motion (ROM), (3) muscle strength, and (4) 5 commonly used functional scores. A visual analogue scale (VAS) was used to evaluate pain at rest, with motion, at night, and worst pain. Our team used a 10-cm scale marked from 'no pain' to 'unbearable pain'. Mean pain scores were calculated and compared. In addition, a score for the worst pain was also recorded. ROM was measured with a goniometer in active forward flexion, abduction, external rotation with the arm at the side, and internal rotation. Internal rotation was measured using vertebral levels, and these were translated into numbers from 1 for the buttocks to 17 for T2. The strength of the supraspinatus (forward elevation in the scapular plane), that of the infraspinatus (external rotation with the arm at the side), and that of the subscapularis ( $\mathrm{SB}$; internal rotation with the arm at the side) were measured with a hand held electronic scale (CHS; CAS Corp, Yangju, Korea). The functional scoring systems used were the American Shoulder and Elbow Surgeons (ASES) system, the Constant system, the University of California at Los Angeles (UCLA) system, the Simple Shoulder Test (SST), and the Shoulder Pain and Disability Index (SPADI) system.

\section{Radiographic Evaluation}

Shoulder x-rays were performed for all patients preoperatively and at the last follow-up. Postoperative radiographs were taken at the time of the last follow-up of the patient. All patients underwent a preoperative computed tomographic arthrography or magnetic resonance imaging to evaluate rotator cuff tendon according to the Cofield type and fatty infiltration according to the Goutallier grade. ${ }^{22)}$ Goutallier grade was measured in supraspinatus, infraspinatus, and SB tendon. Acromiohumeral distances (AHD) and Hamada classification were measured on standard anteroposterior (AP) x-ray. AHD was measured the space between the tangent to the densified inferior edge of the acromion and the parallel tangent to the superior part of the humeral head. ${ }^{23)}$ Glenohumeral joint arthritis was classified according to Hamada et al. ${ }^{20)}$
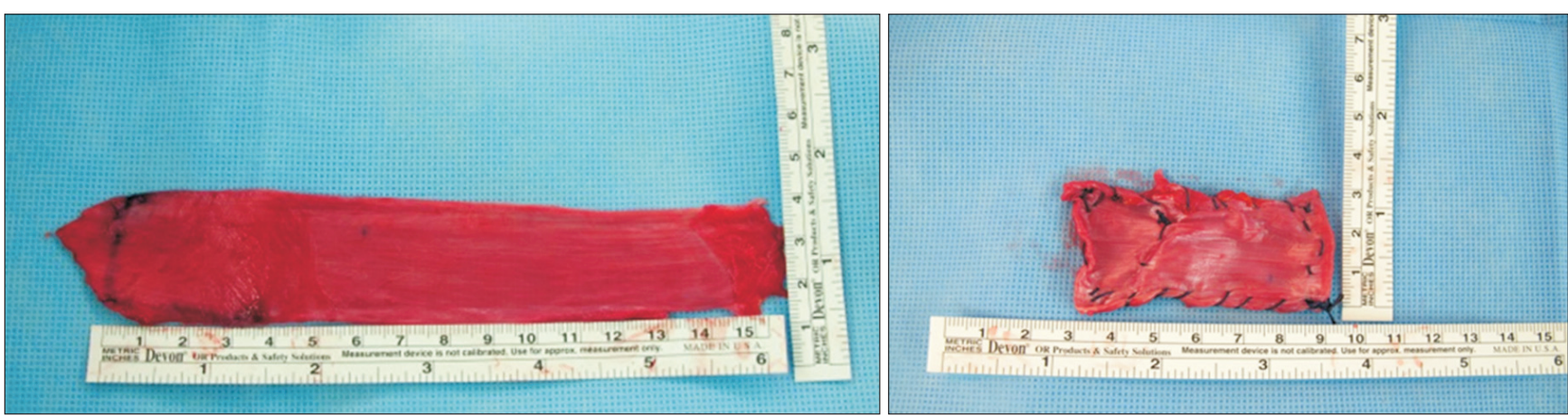

Fig. 1. Preparation of autogenous fascia lata graft. 


\section{Operative Technique}

All arthroscopic surgeries were performed with patients in the lateral decubitus position under general anesthesia. Briefly, systematic glenohumeral joint and subacromial space exploration were performed, and lesions were managed as necessary. The RCT was carefully evaluated, and AP size, mediolateral (ML) retraction, number of involved tendons, visual tendon grade, excursion, and presence of the SB tear were examined. ${ }^{24,25)}$ If the torn tendon is too retracted and can't be mobilized without excessive tension, we performed with ASCR. We repaired the SB torn tendon completely. The greater tuberosity and the superior glenoid were debrided, and only a minimal layer of cortical bone was removed. A measuring probe is used to examine the size of the superior capsule defect. A segment of autogenous fascia lata or dermal allograft two or three times greater in size than the capsular defect was prepared (Fig. 1). The $2 \mathrm{~mm}$ thick dermal allograft was used when the patient did not want to use autograft and had skin problems. Two suture anchors were inserted in the 11 o'clock and 1 o'clock position of the superior glenoid. The glenoid sutures were tied down to the anchors after passing the graft. Next, the lateral aspect of the graft is secured to the rotator cuff footprint using a double-row suture bridge technique with a total of four suture anchors. Using side-to-side sutures with ethibond, the graft is then secured in the AP plane to the remnants of infraspinatus, supraspinatus and SB tendon.

\section{Postoperative Protocol}

The shoulder was protected by an abduction brace for 6 weeks after surgery. Shrugging, protraction, and retraction of shoulder girdles; intermittent exercise of the elbow, wrist, and hand; and external rotation of the arm to neutral with the brace were encouraged as tolerated, usually immediately after surgery. Further passive ROM and active assisted ROM exercises were allowed after the patient was gradually weaned off the abduction brace after 6 weeks. Patients began strengthening exercises after 3 months. Light sports activities, such as jogging, were allowed after 3 months, and full return to sports was allowed after 6 to 9 months according to individual recovery.

\section{Statistical Analysis}

Data analysis was conducted with IBM SPSS Statistics ver. 20 for Windows (IBM Co., Armonk, NY, USA). The Wilcoxon signed-rank test was used for comparison given the small sample size. A $p$-value less than $5 \%$ indicated a statistical significant difference.

\section{Results}

\section{Baseline Patient Characteristics}

Between January 2013 and December 2015, 6 patients underwent ASCR with autogenous fascia lata graft or dermal allograft. All patients were men, and the average age was 59.5 \pm 4.18 years (range, 53-65 years). The average follow-up was $27.33 \pm 7.58$ months (range, 18-36 months). The preoperative tear size was measured intraoperatively (AP: $47.00 \pm 10.54 \mathrm{~mm}$, ML: $44.83 \pm 3.19 \mathrm{~mm}$ ). No other intraoperative or postoperative complications like infection, hematoma or neurological problems occurred. Demographic data are summarized in Table 1.

\section{Clinical Outcomes}

At the last follow-up, VAS pain scores at rest, during motion, at night, and mean pain scores significantly decreased compared

Table 1. Baseline Characteristics of Patients

\begin{tabular}{|c|c|c|c|c|c|c|c|c|c|c|c|c|c|c|c|}
\hline \multirow{2}{*}{$\begin{array}{l}\text { Case } \\
\text { No. }\end{array}$} & \multirow{2}{*}{$\begin{array}{l}\text { Age } \\
(\mathrm{yr})\end{array}$} & \multirow{2}{*}{ Sex } & \multirow{2}{*}{$\begin{array}{l}\text { Domi- } \\
\text { nance }\end{array}$} & \multicolumn{2}{|c|}{ Tear size $(\mathrm{mm})$} & \multirow{2}{*}{$\begin{array}{l}\text { Cofield } \\
\text { type }\end{array}$} & \multirow{2}{*}{$\begin{array}{l}\text { Boileau } \\
\text { stage }\end{array}$} & \multirow{2}{*}{$\begin{array}{l}\text { Involved } \\
\text { tendon }\end{array}$} & \multirow{2}{*}{$\begin{array}{l}\text { SB grade } \\
\text { /treatement }\end{array}$} & \multirow{2}{*}{$\begin{array}{l}\text { Tendon } \\
\text { grade }\end{array}$} & \multirow{2}{*}{$\begin{array}{l}\text { Excur- } \\
\operatorname{sion}^{\ddagger}\end{array}$} & \multirow{2}{*}{$\begin{array}{c}\text { Hamada } \\
\text { classification }\end{array}$} & \multirow{2}{*}{$\begin{array}{c}\text { Goutallier } \\
\text { grade } \\
(\mathrm{SS} / \mathrm{IS} / \mathrm{SB})\end{array}$} & \multirow{2}{*}{ Graft } & \multirow{2}{*}{$\begin{array}{l}\text { Follow- } \\
\text { up } \\
(\mathrm{mo})\end{array}$} \\
\hline & & & & AP & ML & & & & & & & & & & \\
\hline 1 & 61 & Male & Yes & 38 & 42 & Large & IV & SS, IS & & $\mathrm{C}$ & $\mathrm{C}$ & 1 & $3 / 2 / 1$ & TFL autograft & 18 \\
\hline 2 & 59 & Male & Yes & 55 & 45 & Massive & IV & SS, IS & & $\mathrm{C}$ & $\mathrm{C}$ & 2 & $3 / 2 / 1$ & TFL autograft & 32 \\
\hline 3 & 57 & Male & Yes & 60 & 47 & Massive & IV & SS, IS & & $\mathrm{C}$ & $\mathrm{C}$ & 2 & $3 / 4 / 1$ & TFL autograft & 31 \\
\hline 4 & 65 & Male & Yes & 54 & 42 & Massive & IV & SS, IS, SB & 3/repair & $\mathrm{C}$ & $\mathrm{C}$ & 2 & $3 / 2 / 2$ & $\begin{array}{l}\text { Dermal } \\
\text { allograft }\end{array}$ & 36 \\
\hline 5 & 62 & Male & No & 35 & 43 & Large & IV & SS, IS & & $\mathrm{C}$ & $\mathrm{C}$ & 1 & $3 / 2 / 1$ & TFL autograft & 18 \\
\hline 6 & 53 & Male & Yes & 40 & 50 & Massive & IV & SS, IS, SB & 3/repair & $\mathrm{C}$ & $\mathrm{C}$ & 2 & $3 / 3 / 1$ & TFL autograft & 29 \\
\hline
\end{tabular}

AP: anteroposterior, ML: mediolateral, SS: supraspinatus, IS: infraspinatus, SB: subscapularis, TFL: tensor fascia lata.

${ }^{*}$ SB tear was graded according to the Nove-Josserand classification in Pfirrmann et al. ${ }^{25)}$ Grading: $0=$ normal tendon; $1=$ tear less than one-quarter; $2=$ tear more than one-quarter but not complete; 3 = complete tear.

${ }^{\dagger}$ Tendon grade assesses rotator cuff quality using 3 gross tendon criteria: (1) fraying over half of the tendon thickness, (2) delamination of the supraspinatus tendon, and (3) thinning of less than half of the normal thickness. The grades are as follows: A, none of these criteria were met; B, fraying or delamination was identified; and C, both fraying and delamination or thinning regardless of the other criteria.

${ }^{\ddagger}$ Excursion evaluates the lateral displacement of the tear end by manual pulling. Grading: A = over the ridge of the greater tuberosity; $\mathrm{B}=$ within the original footprint in the greater tuberosity; $\mathrm{C}=$ cannot be reduced to the original footprint. 
Table 2. Change in VAS Pain Scores after Arthroscopic Superior Capsular Reconstruction

\begin{tabular}{|c|c|c|c|c|c|c|c|c|c|c|c|c|c|c|c|}
\hline \multirow{2}{*}{$\begin{array}{c}\text { Case } \\
\text { No. }\end{array}$} & \multicolumn{2}{|c|}{ Pain at rest } & \multirow{2}{*}{$p$-value } & \multicolumn{2}{|c|}{ Pain during motion } & \multirow{2}{*}{$p$-value } & \multicolumn{2}{|c|}{ Pain at night } & \multirow{2}{*}{$p$-value } & \multicolumn{2}{|c|}{ Mean pain } & \multirow{2}{*}{$p$-value } & \multicolumn{2}{|c|}{ Worst pain } & \multirow{2}{*}{$p$-value } \\
\hline & Preoperative & Final & & Preoperative & Final & & Preoperative & Final & & Preoperative & Final & & Preoperative & Final & \\
\hline 1 & 3 & 0 & & 3 & 1.67 & & 3 & 0 & & 3 & 0.56 & & 4 & 2 & \\
\hline 2 & 2 & 0 & & 3.33 & 0 & & 3 & 0 & & 2.78 & 0 & & 5 & 1 & \\
\hline 3 & 5 & 1 & & 5 & 1.33 & & 4 & 2 & & 4.67 & 1.44 & & 6 & 7 & \\
\hline 4 & 3 & 0 & & 5.67 & 5.33 & & 7 & 5 & & 5.22 & 3.44 & & 10 & 7 & \\
\hline 5 & 2 & 0 & & 0 & 0 & & 0 & 0 & & 0.67 & 0 & & 3 & 2 & \\
\hline 6 & 3 & 4 & & 8.67 & 5 & & 5 & 4 & & 5.56 & 4.33 & & 9 & 7 & \\
\hline Mean & 3.00 & 0.83 & 0.045 & 4.28 & 2.22 & 0.042 & 3.67 & 1.83 & 0.041 & 3.65 & 1.63 & 0.028 & 6.17 & 4.33 & 0.058 \\
\hline $\mathrm{SD}$ & 1.10 & 1.60 & & 2.92 & 2.40 & & 2.34 & 2.23 & & 1.86 & 1.85 & & 2.79 & 2.94 & \\
\hline
\end{tabular}

VAS: visual analogue scale, SD: standard deviation.

Table 3. Change in ROM after Arthroscopic Superior Capsular Reconstruction

\begin{tabular}{|c|c|c|c|c|c|c|c|c|}
\hline \multirow{2}{*}{ Case No. } & \multicolumn{4}{|c|}{ Preoperative active ROM $\left(^{\circ}\right)$} & \multicolumn{4}{|c|}{ Postoperative active $\mathrm{ROM}\left({ }^{\circ}\right)$} \\
\hline & $\mathrm{FF}$ & Abd. & ER0 & IR0 & $\mathrm{FF}$ & Abd. & ER0 & IR0 \\
\hline 1 & 165 & 180 & 45 & 11 & 160 & 175 & 45 & 11 \\
\hline 2 & 180 & 180 & 45 & 9 & 170 & 175 & 35 & 10 \\
\hline 3 & 180 & 180 & -20 & 11 & 170 & 175 & -5 & 11 \\
\hline 4 & 140 & 130 & 25 & 9 & 130 & 140 & 25 & 7 \\
\hline 5 & 75 & 45 & 40 & 12 & 170 & 170 & 75 & 12 \\
\hline 6 & 170 & 175 & 45 & 11 & 160 & 160 & 30 & 6 \\
\hline Mean & 151.67 & 148.33 & 30.00 & 10.50 & 160.00 & 165.83 & 34.17 & 9.50 \\
\hline $\mathrm{SD}$ & 40.33 & 54.28 & 25.69 & 1.22 & 15.49 & 13.93 & 26.16 & 2.43 \\
\hline
\end{tabular}

ROM: range of motion, FF: forward flexion, Abd.: abduction, ER0: external rotation $0^{\circ}$, IR0: internal rotation $0^{\circ}$, SD: standard deviation.

Table 4. Change in Strength after Arthroscopic Superior Capsular Reconstruction

\begin{tabular}{|c|c|c|c|c|c|c|}
\hline \multirow{2}{*}{ Case No. } & \multicolumn{2}{|c|}{ Strength of SS } & \multicolumn{2}{|c|}{ Strength of IS } & \multicolumn{2}{|c|}{ Strength of SB } \\
\hline & Preoperative & Final & Preoperative & Final & Preoperative & Final \\
\hline 1 & 0 & 5.7 & 5.9 & 9.5 & 10.2 & 11.5 \\
\hline 2 & 6.7 & 7.2 & 5.6 & 6.8 & 8.4 & 15.9 \\
\hline 3 & 8.4 & 8.3 & 0 & 0 & 8.2 & 13.6 \\
\hline 4 & 3.4 & 5.4 & 2.9 & 4.3 & 3.9 & 8.8 \\
\hline Mean & 4.63 & 6.65 & 3.60 & 5.15 & 7.67 & 12.45 \\
\hline SD & 3.72 & 1.35 & 2.75 & 4.04 & 2.67 & 3.02 \\
\hline
\end{tabular}

SS: supraspinatus, IS: infraspinatus, SB: subscapularis, SD: standard deviation.

with those before surgery $(p=0.045,0.042,0.041,0.028$, respectively). No difference was found in worst pain score (Table 2).

No significant difference between before and after surgery was found for active forward flexion, abduction, external rotation with the arm at the side, and internal rotation (all $p>0.05$ ) (Table 3).

Among patients, 2 patients (case 5, 6) did not check the strength with a hand held electronic scale. Strength of the supraspinatus, infraspinatus, and SB muscles were not significantly different among 4 patients before and after surgery (all $p>0.05$ ) (Table 4).

\section{Functional Outcomes}

Significant differences were seen in the Constant, ASES, 
Table 5. Change in Functional Outcomes after Arthroscopic Superior Capsular Reconstruction

\begin{tabular}{|c|c|c|c|c|c|c|c|c|c|c|c|c|c|c|c|}
\hline \multirow{2}{*}{$\begin{array}{l}\text { Case } \\
\text { No. }\end{array}$} & \multicolumn{2}{|c|}{ Constant score } & \multirow{2}{*}{$p$-value } & \multicolumn{2}{|c|}{ ASES score } & \multirow{2}{*}{$p$-value } & \multicolumn{2}{|c|}{ UCLA score } & \multirow{2}{*}{$p$-value } & \multicolumn{2}{|c|}{ SST score } & \multirow{2}{*}{$p$-value } & \multicolumn{2}{|c|}{ SPADI score } & \multirow{2}{*}{$p$-value } \\
\hline & Preoperative & Final & & Preoperative & Final & & Preoperative & Final & & Preoperative & Final & & Preoperative & Final & \\
\hline 1 & 66 & 73.7 & & 73.33 & 87.22 & & 22 & 31 & & 9 & 12 & & 23.08 & 10 & \\
\hline 2 & 66.7 & 80.2 & & 59.44 & 100 & & 20 & 33 & & 6 & 12 & & 36.15 & 1.54 & \\
\hline 3 & 67.4 & 70.3 & & 58.33 & 86.11 & & 16 & 31 & & 7 & 12 & & 37.69 & 15.38 & \\
\hline 4 & 54.4 & 56.4 & & 45.56 & 54.44 & & 8 & 28 & & 6 & 10 & & 71.54 & 56.15 & \\
\hline 5 & 48 & 91 & & 78.33 & 100 & & 17 & 33 & & 7 & 12 & & 16.15 & 1.54 & \\
\hline 6 & 56.9 & 63 & & 47.22 & 61.67 & & 18 & 24 & & 2 & 6 & & 49.23 & 42.31 & \\
\hline Mean & 59.90 & 72.43 & 0.028 & 60.37 & 81.57 & 0.028 & 16.83 & 30.00 & 0.028 & 6.17 & 10.67 & 0.027 & 38.97 & 21.15 & 0.028 \\
\hline SD & 7.31 & 11.23 & & 12.16 & 17.63 & & 4.41 & 3.16 & & 2.11 & 2.21 & & 18.02 & 20.81 & \\
\hline
\end{tabular}

ASES: American Shoulder and Elbow Surgeons, UCLA: University of California at Los Angeles, SST: Simple Shoulder Test, SPADI: Shoulder Pain and Disability Index, SD: standard deviation.

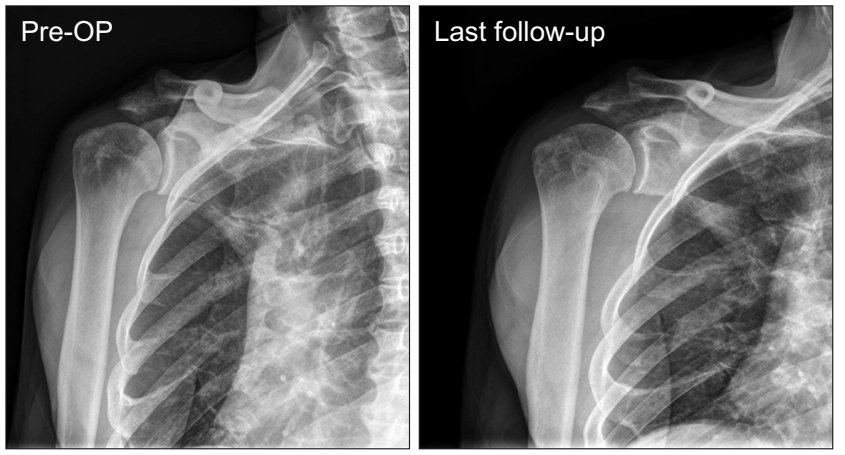

Fig. 2. Anteroposterior radiograph of right shoulder before and after arthroscopic superior capsular reconstruction with autogenous fascia lata graft. The acromiohumeral distance was $7.1 \mathrm{~mm}$ preoperatively (Pre-OP) and improved to $7.5 \mathrm{~mm}$ at last follow-up.

UCLA, SST, and SPADI scores (all $p<0.05$ ). At final follow-up after surgery, all scores were more improved than those before surgery in all 6 patients (Table 5).

\section{Radiographic Results}

AHD in x-ray were not different significantly between before and after surgery. The AHD was mean of $4.79 \pm 2.25 \mathrm{~mm}$ at preoperatively and decreased to $3.75 \pm 2.75 \mathrm{~mm}$ at final follow-up. Only 1 patient showed the improvement after surgery (Fig. 2). Concerning the Hamada score, 4 patients had no change and 2 patients progressed arthritis (Hamada score 5, 5, respectively) (Table 6). In the case of dermal allograft, AHD decreased and head collapsed during 3 years follow-up (Fig. 3A). The dermal allograft appeared to resorb or melt after 6 weeks (Fig. 3B).

\section{Discussion}

This study shows that ASCR is a reproducible procedure that
Table 6. Change in Acromiohumeral Distance and Hamada Classification after Arthroscopic Superior Capsular Reconstruction

\begin{tabular}{|c|c|c|c|c|c|}
\hline \multirow{2}{*}{$\begin{array}{c}\text { Case } \\
\text { No. }\end{array}$} & \multicolumn{2}{|c|}{ Acromiohumeral distance ( $\mathrm{mm}$ ) } & \multirow{2}{*}{$p$-value } & \multicolumn{2}{|c|}{ Hamada classification } \\
\hline & Preoperative & Final & & Preoperative & Final \\
\hline 1 & 7.1 & 7.5 & & 1 & 1 \\
\hline 2 & 3.42 & 1.43 & & 2 & 2 \\
\hline 3 & 6.3 & 5.9 & & 1 & 1 \\
\hline 4 & 3.2 & 1.3 & & 2 & 5 \\
\hline 5 & 6.92 & 5.1 & & 1 & 1 \\
\hline 6 & 1.82 & 1.3 & & 2 & 5 \\
\hline Mean & 4.79 & 3.75 & 0.058 & & \\
\hline SD & 2.25 & 2.75 & & & \\
\hline
\end{tabular}

SD: standard deviation.

leads to pain reduction and functional improvement in patients with massive, irreparable RCT. Since the report of Mihata et al., ${ }^{14)}$ ASCR is a recently-developed technique for the surgical treatment of massive, irreparable RCTs. So far there have been 3 clinical studies, to our knowledge, that investigated clinical outcomes of ASCR. ${ }^{15-17)}$ In these three studies, ASES and AHD were commonly used to evaluate outcomes after ASCR.

Mihata et al. ${ }^{15)}$ showed that all measured clinical outcomes improved significantly: ASES scores improved from 23.5 to 92.9, Japanese Orthopaedic Association (JOA) score improved from 48.3 to 92.6 , and UCLA improved from 9.9 to 32.4. Denard et al. ${ }^{16)}$ reported that ASCR with dermal allograft improved clinical outcomes significantly: ASES scores improved from 43.6 to 77.6, subjective shoulder value improved from 35.0 to 76.3. Hirahara et al. ${ }^{17)}$ used dermal allograft and reported that ASES improved from 41.8 to 86.5. We also showed improvement in Constant, ASES, UCLA, SST, and SPADI scores following ASCR. Concerning the pain outcome, the results of this study are in agreement 


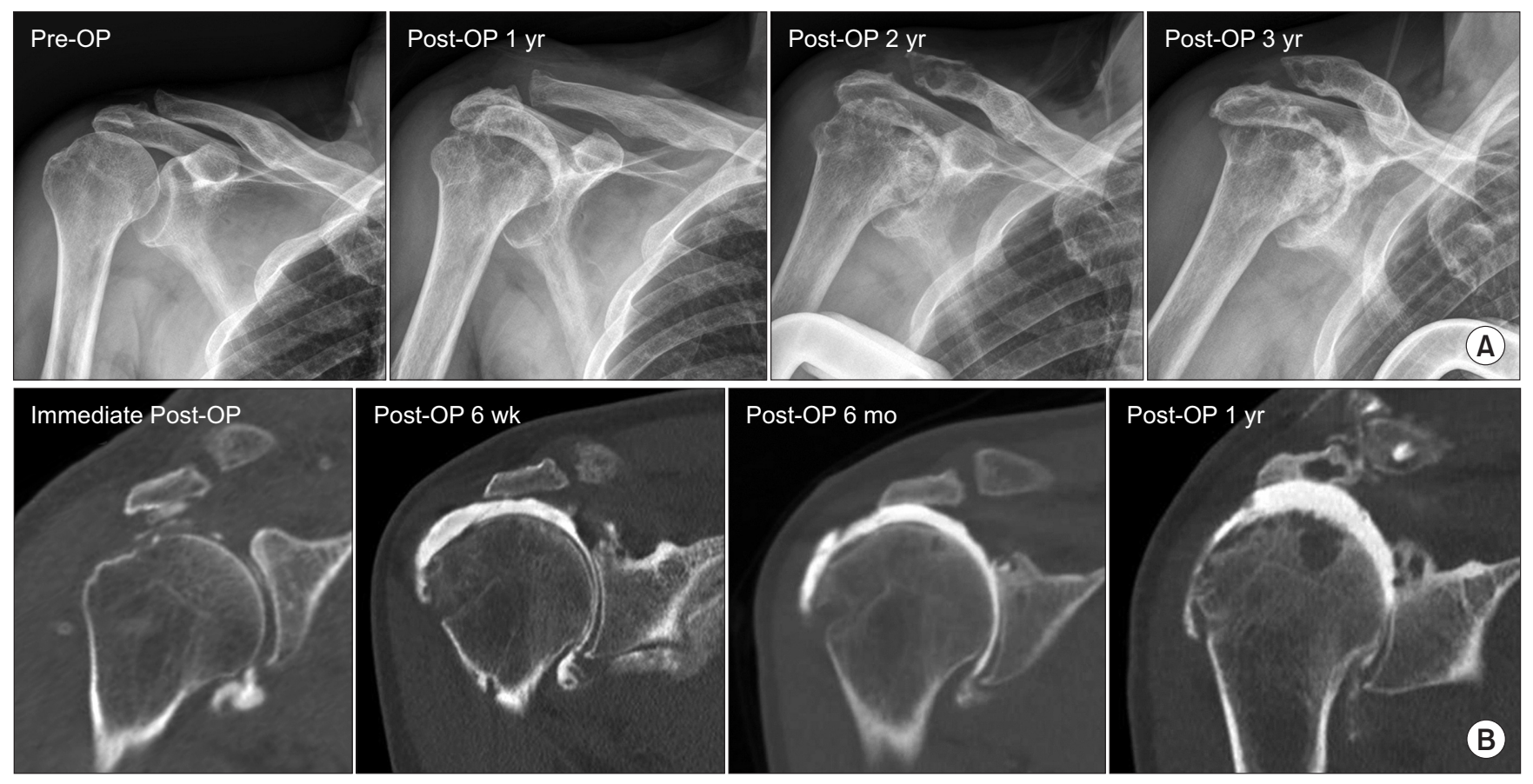

Fig. 3. (A) Anteroposterior radiograph of right shoulder before and after arthroscopic superior capsular reconstruction with dermal allograft. The acromiohumeral distance was $3.2 \mathrm{~mm}$ preoperatively (Pre-OP) and decreased to $1.3 \mathrm{~mm}$ at last follow-up. (B) Computed tomography angiography imaging after surgery. Six weeks after surgery, graft was not in place.

Post-OP: postoperative.

with the two studies ${ }^{16,17)}$ Denard et al. ${ }^{16)}$ was categorized as successful outcomes if the ASES score was $>50$ at last follow-up and 17-point improvement after ASCR. Based on this criteria for successful treatment, they reported $67.8 \%$ were considered a success, Mihata et al..$^{15)}$ and Hirahara et al. ${ }^{17)}$ can be considered $100 \%$. When compared with other studies, the successful rate was $50 \%$ in our study. Two of six patients had a decrease in $\mathrm{AHD}$, and the osteoarthritis progressed after ASCR (postoperative Hamada classification was 5). One of these two patients used a $2 \mathrm{~mm}$ thick dermal allograft and one used an autologous fascia lata graft. Biomechanically, glenohumeral translation increases in all planes if there is a defect in superior cupsule. ${ }^{14)}$ Therefore, it can be thought that graft failure occurred when AHD decreased and osteoarthritis progressed. In our case with dermal allograft, there was a decrease in AHD, and head was collapsed after postoperative 6 weeks. This can be thought of as two reasons. First, Mihata et al. ${ }^{26)}$ reported that biomechanical study showed the SCR using a $8 \mathrm{~mm}$ thick graft restores superior stability. Denard et al. ${ }^{16)}$ recommended using a $3 \mathrm{~mm}$ thick dermal allograft because the $1 \mathrm{~mm}$ thick graft showed only $40 \%$ success rate. Although we may not be using the $2 \mathrm{~mm}$ thick allodermal graft as the precise cause of failure, we can be thought that the graft is thinner than normal fascial lata graft and preoperative AHD was 1.82 , which was very narrow. Second, the possibility of an immune reaction by allograft is not ruled out. Although we did not perform a morphological study, suspicious finding of infection were not seen when we performed aspiration and laboratory finding. Using allografts is related to a decreased operation time, no donor-site morbidity when compared to autograft. Allograft also has disadvantages, like the risk of the potential for immune reaction, and delayed graft incorporation. ${ }^{27}$

Mihata et al. ${ }^{15)}$ and Denard et al. ${ }^{16)}$ reported that ROM increased significantly after ASCR. However, there was no significant difference in our study. In the results of Mihata's study, ${ }^{15)}$ ROM was increased in all 13 patients in the preoperative ROM below 90 degrees, but only in 6 of 11 patients above 90 degrees. It is difficult to know the pseudoparalysis or limitation of motion preoperatively, because there were no results on ROM passively in their study. ROM is below 90 degrees preoperatively, which is considered statistically significant. In our study, most patients had similar or increased postoperative ROM, and 1 patient with pseudoparalysis could see increased active ROM.

Of the three clinical studies, only Mihata et al. ${ }^{15)}$ reported about the muscle strength after ASCR. They reported that shoulder abduction and external rotation strength were all improvements from manual muscle testing grade $3+$ to 5 - and the recovery of strength could produce better results compared to other surgical treatments for massive, irreparable RCT. ${ }^{15)}$ Our cases showed that the strength of the SS and IS were increased in 3 of 4 patients. And among the 4 cases, strength of the SB was increased in the 3 patients without SB tear.

There are some limitations of this study. First, the final follow- 
up ranged from 18 to 36 months. Second, there was only one patient with ASCR with dermal allograft, which was too small to be evaluated for allograft. However, since the studies about the immune reaction have not been reported in failure for ASCR with allograft. In a future study, it will be necessary to study about the immune reaction by using the allograft.

\section{Conclusion}

In conclusion, our results support the ASCR as a viable treatment for surgical salvage in massive, irreparable RCTs. This treatment option may provide patients with decreased pain and increased function. And studying our case of dermal allograft failure provides opportunities to decrease graft failure in ASCR using dermal allograft.

\section{References}

1. Rockwood CA Jr, Williams GR Jr, Burkhead WZ Jr. Débridement of degenerative, irreparable lesions of the rotator cuff. J Bone Joint Surg Am. 1995;77(6):857-66.

2. Chen KH, Chiang ER, Wang HY, Ma HL. Arthroscopic partial repair of irreparable rotator cuff tears: factors related to greater degree of clinical improvement at 2 years of follow-up. Arthroscopy. 2017;33(11):1949-55.

3. Burkhart SS, Nottage WM, Ogilvie-Harris DJ, Kohn HS, Pachelli A. Partial repair of irreparable rotator cuff tears. Arthroscopy. 1994;10(4):363-70.

4. Gerber C, Rahm SA, Catanzaro S, Farshad M, Moor BK. Latissimus dorsi tendon transfer for treatment of irreparable posterosuperior rotator cuff tears: long-term results at a minimum follow-up of ten years. J Bone Joint Surg Am. 2013;95(21):19206.

5. Grimberg J, Kany J, Valenti P, Amaravathi R, Ramalingam AT. Arthroscopic-assisted latissimus dorsi tendon transfer for irreparable posterosuperior cuff tears. Arthroscopy. 2015;31(4):599607.e1.

6. Gavriilidis I, Kircher J, Magosch P, Lichtenberg S, Habermeyer P. Pectoralis major transfer for the treatment of irreparable anterosuperior rotator cuff tears. Int Orthop. 2010;34(5):689-94.

7. Bond JL, Dopirak RM, Higgins J, Burns J, Snyder SJ. Arthroscopic replacement of massive, irreparable rotator cuff tears using a Graftjacket allograft: technique and preliminary results. Arthroscopy. 2008;24(4):403-9.e1.

8. Mori D, Funakoshi N, Yamashita F. Arthroscopic surgery of irreparable large or massive rotator cuff tears with lowgrade fatty degeneration of the infraspinatus: patch autograft procedure versus partial repair procedure. Arthroscopy. 2013;29(12):1911-21.

9. Senekovic V, Poberaj B, Kovacic L, Mikek M, Adar E, Dekel A. Prospective clinical study of a novel biodegradable sub- acromial spacer in treatment of massive irreparable rotator cuff tears. Eur J Orthop Surg Traumatol. 2013;23(3):311-6.

10. Senekovic V, Poberaj B, Kovacic L, et al. The biodegradable spacer as a novel treatment modality for massive rotator cuff tears: a prospective study with 5-year follow-up. Arch Orthop Trauma Surg. 2017;137(1):95-103.

11. Ramirez MA, Ramirez J, Murthi AM. Reverse total shoulder arthroplasty for irreparable rotator cuff tears and cuff tear arthropathy. Clin Sports Med. 2012;31(4):749-59.

12. Cuff D, Clark R, Pupello D, Frankle M. Reverse shoulder arthroplasty for the treatment of rotator cuff deficiency: a concise follow-up, at a minimum of five years, of a previous report. J Bone Joint Surg Am. 2012;94(21):1996-2000.

13. Galasso O, Familiari F, Gasparini G. Treatment options for irreparable postero-superior cuff tears in young patients. World J Orthop. 2015;6(10):770-5.

14. Mihata T, McGarry MH, Pirolo JM, Kinoshita M, Lee TQ. Superior capsule reconstruction to restore superior stability in irreparable rotator cuff tears: a biomechanical cadaveric study. Am J Sports Med. 2012;40(10):2248-55.

15. Mihata T, Lee TQ, Watanabe $C$, et al. Clinical results of arthroscopic superior capsule reconstruction for irreparable rotator cuff tears. Arthroscopy. 2013;29(3):459-70.

16. Denard PJ, Brady PC, Adams CR, Tokish JM, Burkhart SS. Preliminary results of arthroscopic superior capsule reconstruction with dermal allograft. Arthroscopy. 2018;34(1):93-9.

17. Hirahara AM, Andersen WJ, Panero AJ. Superior capsular reconstruction: clinical outcomes after minimum 2-year followup. Am J Orthop (Belle Mead NJ). 2017;46(6):266-78.

18. Tokish JM, Beicker C. Superior capsule reconstruction technique using an acellular dermal allograft. Arthrosc Tech. 2015;4(6):e833-9.

19. Fuchs B, Weishaupt D, Zanetti M, Hodler J, Gerber C. Fatty degeneration of the muscles of the rotator cuff: assessment by computed tomography versus magnetic resonance imaging. J Shoulder Elbow Surg. 1999;8(6):599-605.

20. Hamada K, Fukuda H, Mikasa M, Kobayashi Y. Roentgenographic findings in massive rotator cuff tears. A long-term observation. Clin Orthop Relat Res. 1990;(254):92-6.

21. Gerber C, Wirth SH, Farshad M. Treatment options for massive rotator cuff tears. J Shoulder Elbow Surg. 2011;20(2 Suppl):S20-9.

22. Goutallier D, Postel JM, Bernageau J, Lavau L, Voisin MC. Fatty muscle degeneration in cuff ruptures. Pre- and postoperative evaluation by CT scan. Clin Orthop Relat Res. 1994;(304):7883.

23. Goutallier D, Le Guilloux P, Postel JM, Radier C, Bernageau J, Zilber S. Acromio humeral distance less than six millimeter: its meaning in full-thickness rotator cuff tear. Orthop Traumatol Surg Res. 2011;97(3):246-51.

24. Jo $\mathrm{CH}$, Yoon $\mathrm{KS}$, Lee JH, et al. The effect of multiple channel- 
ing on the structural integrity of repaired rotator cuff. Knee Surg Sports Traumatol Arthrosc. 2011;19(12):2098-107.

25. Pfirrmann CW, Zanetti M, Weishaupt D, Gerber C, Hodler J. Subscapularis tendon tears: detection and grading at MR arthrography. Radiology. 1999;213(3):709-14.

26. Mihata T, McGarry MH, Kahn T, Goldberg I, Neo M, Lee TQ. Biomechanical effect of thickness and tension of fascia lata graft on glenohumeral stability for superior capsule reconstruction in irreparable supraspinatus tears. Arthroscopy. 2016;32(3):418-26.

27. Chang SK, Egami DK, Shaieb MD, Kan DM, Richardson AB. Anterior cruciate ligament reconstruction: allograft versus autograft. Arthroscopy. 2003;19(5):453-62. 